\title{
A manipulação das consciências em tempos de barbárie e a criminalização da juventude negra no Brasil
}

\section{The manipulation of the consciousness in the present barbarism and the criminalization about the of the black youth in Brazil}

\author{
Jaqueline Garcez Buozi ${ }^{a}$
}

Resumo: Neste artigo, buscamos refletir sobre a relação entre a manipulação das consciências e a naturalização das manifestações mais expressivas da barbárie atual no Brasil, o superencarceramento e genocídio da juventude negra. A partir do referencial teórico marxista, refletimos sobre o processo de consciência do ser social e o caráter manipulatório da esfera jurídica, destacando o papel fundamental que exerce no processo de criminalização e naturalização da barbárie.

Palavras-chave: Consciência. Criminalização seletiva. Ideologia. Direito. Manipulação.
Abstract: In the present article, we seek to reflect on the relationship between the manipulation of the consciousness and the naturalization of the most expressive manifestations of barbarism in the present Brazilian scenario, the over imprisoment and the genocide of black youth. From the Marxist theoretical framework, we reflect on the process of consciousness of the social being and, then, we analyze the manipulative character of the juridical sphere and the key role it plays in the process of selective criminalization and naturalization of barbarism.

Keywords: Consciousness. Selective Criminalization. Ideology. Law. Manipulation.

\section{Introdução}

Bem-vindos ao espetáculo Todos os espectadores Facção Central apresenta $O$ circo dos horrores

Facção Central 


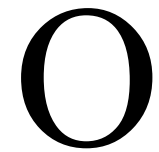
tema apresentado neste artigo tem como objetivo refletir sobre a relação entre a manipulação das consciências e a naturalização das manifestações mais expressivas da barbárie atual. A partir desse recorte, buscamos revelar, introdutoriamente, alguns elementos que compõem o atual fenômeno do grande encarceramento e genocídio da juventude negra no Brasil. Assim, visando buscar os fundamentos reais, econômicos e ideoculturais do que está em curso, as reflexões sintetizadas neste artigo têm como referencial teórico a tradição marxista.

A reestruturação produtiva do capital, segundo Netto (2012, p. 417), tem caracterizado uma "extraordinária economia do trabalho vivo, elevando brutalmente a composição orgânica do capital; resultado direto na sociedade capitalista: o crescimento exponencial da força de trabalho excedentária em face dos interesses do capital".

Dentre outras transformações societárias que emergiram com a crise do capital, há uma nova onda punitiva que, segundo Menegat (informação verbal), ${ }^{1}$ configura-se através de duas formas que objetivam administrar o desmoronamento social causado pela crise estrutural do capital, a qual afeta todas as esferas constitutivas da vida social em âmbito global.

A primeira forma de gestão das massas ociosas consiste na ampliação das prisões e no grande encarceramento, travestida pela guerra contra as drogas iniciada na virada do século XX para o XXI. A partir dos anos 1980, foram registrados aumentos exorbitantes no número de instituições prisionais e da população carcerária, em sua maioria negra, motivados pelo Movimento de Lei e Ordem ${ }^{2}$ imposto pelos Estados Unidos, o qual representa a máxima

1. Seminário Direito e Marxismo, Universidade Federal de Santa Catarina, 2013 - Painel Criminologia Crítica - UFSC.

2. Cabe destacar que as Leis de Jim Crow, que institucionalizaram a segregação racial nos estados do Sul dos EUA, vigoraram até 1965. Portanto, novas formas foram criadas pela sociedade burguesa para manter o controle social, através da segregação racial. "Um dos princípios do 'Movimento de Lei e Ordem' separa a sociedade em dois grupos: o primeiro, composto de pessoas de bem, merecedoras de proteção legal; o segundo, de homens maus, os delinquentes, aos quais se endereça toda a rudeza e severidade da lei penal.” Disponível em: <http://www.ambitojuridico.com.br/site/index.php?n_link=revista_artigos_leitura\&artigo_id=7938>. Acesso em: 8 mar. 2017. 
repressão e a expansão de leis incriminadoras. $\mathrm{O}$ aumento do encarceramento ocorre, portanto, em escala mundial, haja vista a relação entre a criminalização ${ }^{3}$ seletiva e o processo de acumulação do capital.

Os dados divulgados no último Levantamento Nacional de Informações Penitenciárias, ${ }^{4}$ atualizado em junho de 2016 e publicado em dezembro de 2017 pelo Ministério da Justiça e Segurança Pública, são ainda mais impactantes do que o levantamento realizado em 2014. ${ }^{5}$ Enquanto, naquele ano, o Brasil registrou um aumento de $575 \%$ na população prisional desde 1990 , dois anos depois o crescimento chegou a 707\%.

Atrás apenas dos Estados Unidos e da China, o país ultrapassou a Rússia e ocupou a terceira posição entre as nações que mais prendem no mundo, registrando uma taxa de crescimento de $7,3 \%$ ao ano, enquanto a taxa de crescimento populacional brasileira é de $0,77 \%$ e está declinando nos últimos anos, segundo pesquisa publicada pelo IBGE agosto de $2017 .{ }^{6}$

A proporção de pessoas presas para cada 100 mil habitantes era de 137 nos anos 2000, saltou para 306,2 em 2014 e atingiu 352,6 em junho de 2016, no tempo em que a média mundial era de 144 . Desse modo, a população carcerária brasileira chegou a 726.712 pessoas.

Cabe ainda destacar que $40 \%$ das pessoas estavam presas sem ter sido julgadas, sendo que nas unidades prisionais que informaram o dado, cerca

3. A prisão, desde a sua origem, nunca foi um mecanismo de combate ao crime, mas um instrumento de controle de determinado grupo social em cada época da forma social hoje hegemônica. Partimos do conceito de criminalização como o ato de imputar crime ou tomar como crime as ações de determinados grupos sociais: "[...] a transformação em sistemas penais não pode ser explicada somente pela mudança das demandas da luta contra o crime, embora essa luta faça parte do jogo. Todo sistema de produção tende a descobrir formas punitivas que correspondem às suas relações de produção. É, pois, necessário pesquisar a origem e a força dos sistemas penais, o uso e a rejeição de certas punições e a intensidade das práticas penais, uma vez que elas são determinadas pelas forças sociais” (Rusche e Kirchheimer, 2004, p. 20).

4. Disponível em: $<$ http://depen.gov.br/DEPEN/noticias-1/noticias/infopen-levantamento-nacional-de-informacoes-penitenciarias-2016/relatorio_2016_22111.pdf>. Acesso em: 18 jan. 2018.

5. Disponível em: <http://www.justica.gov.br/seus-direitos/politica-penal/infopen_dez14.pdf/@@ download/file>. Acesso em: 10 mar. 2017.

6. Disponível em: <http://www.brasil.gov.br/cidadania-e-justica/2017/08/populacao-brasileira-passa-de-207-7-milhoes-em-2017>. Acesso em: 18 jan. 2018. 
de $47 \%$ dos presos provisórios estavam custodiados há mais de noventa dias aguardando julgamento. Com isso, dentre os cinco países com maior população carcerária, o Brasil também está entre as maiores taxas de presos sem condenação, ficando à frente dos Estados Unidos, cujo percentual é de 20\%.

Analisados os dados que demonstram o perfil dos presos, nota-se que esse "rigor" penal apresenta evidente seletividade: $64 \%$ dos presos são negros, enquanto na população brasileira em geral, a proporção é significativamente menor (46\%); 55\% têm entre 18 e 29 anos, e $19 \%$ entre 30 e 34 anos; $51 \%$ possuem o ensino fundamental incompleto; $14 \%$, apenas o ensino fundamental, $6 \%$ foram alfabetizados sem cursos regulares e $4 \%$ não foram alfabetizados. ${ }^{7}$ Sobre os tipos penais, a maioria consiste em crimes contra o patrimônio (40\%) e tráfico de drogas $(28 \%)$.

Esse panorama torna-se, ainda, mais alarmante se considerados os mandados de prisão aguardando cumprimento, ${ }^{8}$ as prisões domiciliares e os adolescentes em cumprimentos de medidas privativas de liberdade. Caso sejam computados, o Brasil se aproximará de 1, 5 milhão de pessoas.

Concomitante ao superencarceramento demonstrado pelos dados supracitados, a segunda forma de gestão das massas, de acordo com Menegat (informação verbal), ${ }^{9}$ refere-se à cruel "contribuição" que o Brasil oferece ao mundo: o genocídio da juventude negra. A cada 23 minutos um jovem negro é morto no Brasil; cerca de 23,1 mil jovens negros são assassinados

7. O levantamento aponta que "ao observarmos a participação dos jovens na população brasileira total, é possível afirmar que essa faixa etária está sobrerrepresentada no sistema prisional: a população entre 18 e 29 anos representa $18 \%$ da população total no Brasil e 55\% da população no sistema prisional no mesmo ano". Já "a informação sobre a raça, cor ou etnia da população prisional estava disponível para 493.145 pessoas (ou $72 \%$ da população prisional total). A partir da análise da amostra de pessoas sobre as quais foi possível obter dados acerca da raça, cor ou etnia, podemos afirmar que $64 \%$ da população prisional é composta por pessoas negras. Na população brasileira acima de 18 anos, em 2015, a parcela negra representa 53\%, indicando a sobrerrepresentação desse grupo populacional no sistema prisional" Disponível em: $<\mathrm{http}: / \mathrm{depen}$. gov.br/DEPEN/noticias-1/noticias/infopen-levantamento-nacional-de-informacoes-penitenciarias-2016/ relatorio_2016_22111.pdf $>$. Acesso em: 18 jan. 2018.

8. Em 2014, correspondiam a cerca de 500 mil. Em janeiro de 2018, constavam abertos cerca de 608 mil mandados. Disponível em: <http://www.cnj.jus.br/bnmp/\#/relatorio>. Acesso em: 18 jan. 2018.

9. Seminário Direito e Marxismo, Universidade Federal de Santa Catarina, 2013 — Painel Criminologia Crítica - UFSC. 
anualmente no país, a maioria durante ações policiais; os homicídios de jovens negros, de 15 a 29 anos, é quatro vezes maior quando comparado aos jovens brancos; aos 21 anos apresentam um risco 147\% maior quando comparados aos brancos, amarelos e indígenas. ${ }^{10}$

Para pensar de que forma tais soluções barbarizantes do capital para a vida social são tratadas como naturais e (re)produzidas acriticamente no cotidiano ${ }^{11}$ da sociedade brasileira, partimos de uma reflexão sobre o processo de consciência do ser social, destacando a sua forma elementar, ou seja, a sua primeira manifestação.

Em seguida, apontamos o caráter manipulatório da esfera jurídica e o papel fundamental que exerce no processo de criminalização seletiva, naturalização da violência estatal e reprodução do capital.

Por fim, tecemos um breve comentário acerca da produção e reprodução dos estereótipos, através dos meios de comunicação, que legitimam a criminalização da juventude pobre, sobretudo negra.

\title{
0 processo de consciência do ser social e a naturalização da criminalização
}

\author{
Na televisão \\ A verdade não importa \\ É negro, favelado, então tava de pistola \\ MC Carol
}

O movimento da consciência, assim como o movimento da realidade, possui um caráter dialético e, desta forma, não pode ser considerado algo linear. Assim, esse movimento é constituído por formas de consciência que representam tanto o rompimento quanto a continuidade, isto é, encontra sua

10. Disponível em: $<$ http://www.ipea.gov.br/portal/images/stories/PDFs/nota_tecnica/160322_nt_17_ atlas_da_violencia_2016_finalizado.pdf $>$. Acesso em: 8 mar. 2017.

11. Entendido neste artigo como espaço de reprodução da imediaticidade da vida social. 
determinação material no movimento do ser social..$^{12}$ Acerca desse processo, ${ }^{13}$ o professor Iasi (2011, p. 11) explica que:

[...] cada momento traz em si os elementos de sua superação, em que as formas já incluem contradições que, ao amadurecerem, remetem a consciência para novas formas e contradições, de maneira que o movimento se expressa num processo que contém saltos e recuos.

Trata-se, ainda, de um processo ao mesmo tempo particular e universal, na medida em que "a partir da diversidade de manifestações particulares podemos encontrar, nitidamente, uma linha universal quando falamos em consciência de classe" (Iasi, 2011, p. 13). Desta forma, quando pensamos sobre a classe trabalhadora, a consciência ora é moldada pela ordem do capital, ora pela busca de seus próprios interesses.

Para melhor compreender esse fenômeno, ao analisar o desenvolvimento da consciência, Iasi (2011) trata das três formas dialéticas desse processo: a forma elementar, a segunda forma de consciência denominada de consciência em si e a terceira forma ou consciência para si.

Considerando os limites e os propósitos deste artigo, enfocaremos a primeira manifestação da consciência, a qual possui como um de seus mecanismos básicos a ultrageneralização, ou seja, "a captação de um concreto aparente, limitado, uma parte do todo e do movimento de sua entificação". Constitui-se, nesse momento, da interiorização das relações vividas pelo indivíduo. Contudo, não se trata de interiorizar as relações em si, mas sim os "seus valores, normas, padrões de conduta e concepções" (Iasi, 2011, p. 14).

Desse modo, de acordo com Iasi (2011, p. 18), a constituição das características da forma elementar da consciência tem como elementos principais:

12. Lukács (2013, p. 41) define o ser social como um "complexo composto de complexos", cujas categorias ontológicas sociais fundamentais, como o trabalho, a linguagem, a cooperação e a divisão do trabalho, não podem ser adequadamente compreendidas se consideradas isoladamente.

13. "Falamos em processo de consciência e não em consciência porque não a concebemos com uma coisa que possa ser adquirida e que, portanto, antes de sua posse, poderíamos supor um estado de não consciência" (Iasi, 2011, p. 12). 
1. a vivência de relações que já estavam preestabelecidas como realidade dada; 2. a percepção da parte pelo todo, onde o que é vivido particularmente como uma realidade pontual torna-se "a realidade" (ultrageneralização);

3. por esse mecanismo, as relações vividas perdem seu caráter histórico e cultural para se tornarem naturais, levando à percepção de que "sempre foi assim e sempre será";

4. a satisfação das necessidades, seja de sobrevivência ou do desejo, deve respeitar a forma e a ocasião que não são definidos por quem sente, mas pelo outro que tem o poder de determinar o quando e o como;

5. essas relações não permanecem externas, mas se interiorizam como normas, valores e padrões de comportamento, formando com o SUPEREGO, um componente que o indivíduo vê como dele, como autocobrança e não como uma exigência externa;

6. na luta entre a satisfação do desejo e a sobrevivência, o indivíduo tende a garantir a sobrevivência, reprimindo ou deslocando o desejo;

7. assim, o indivíduo submete-se às relações dadas e interioriza os valores como seus, zelando por sua aplicação, desenvolvimento e reprodução.

Diante desses elementos, destacamos para a compreensão do nosso tema que, em uma sociedade burguesa, as ideias e interesses do capital são, portanto, reproduzidas e naturalizadas na medida em que o indivíduo toma como geral a realidade que se apresenta imediata e particularmente. Ainda nas palavras do autor (p. 21):

Quando, numa sociedade de classes, uma delas detém os meios de produção, tende a deter também os meios para universalizar sua visão de mundo e suas justificativas ideológicas a respeito das relações sociais de produção que garantem sua dominação econômica.

Neste sentido, essa forma inicial da consciência "expressa-se como alienação" e pode ser considerada como "a base, o terreno fértil, onde será plantada a ideologia como forma de dominação". Entretanto, é necessário apontar que ela "apresenta-se como alienação não porque se desvincula da 
realidade, mas pelo fato de naturalizá-la, por desvincular os elementos componentes da visão de mundo de seu contexto e de sua história” (Iasi, 2011, p. 20).

Os homens são os produtores de suas representações, de suas ideias e assim por diante, mas os homens reais, ativos, tal como são condicionados por um determinado desenvolvimento de suas forças produtivas e pelo intercâmbio que a ele corresponde, até chegar às suas formações mais desenvolvidas. A consciência (Bewusstsein) não pode jamais ser outra coisa do que o ser consciente (bewusste Sein), e o ser dos homens é o seu processo de vida real. Se, em toda ideologia, os homens e suas relações aparecem de cabeça para baixo como numa câmara escura, este fenômeno resulta do seu processo histórico de vida [...]. (Marx e Engels, 2007, p. 94)

Destarte, a materialidade das relações que produzem a alienação e se expressam no universo das ideias como ideologia deve ser compreendida a partir da relação entre trabalho e capital, pois, ao mesmo tempo em que o trabalho é considerado fundante do ser social e do processo de humanização, sob o império da mercadoria, ele deixa de ser livre ao ser transformado em trabalho assalariado, alienado, fetichizado. Desta forma, "sob o capitalismo, o trabalhador frequentemente não se satisfaz no trabalho, mas se degrada; não se reconhece, mas muitas vezes recusa e se desumaniza no trabalho" (Antunes, 2013, p. 9).

Ao recordar Marx, Antunes (2013, p. 8-9) afirma que, com o modo como se organiza o trabalho e a vida a partir dos ditames do modo de produção capitalista, "o homem estranha-se em relação ao próprio homem, tornando-se estranho em relação ao gênero humano". Posto isso, em síntese, a alienação se expressa a partir de três aspectos: "a) o ser humano está alienado da natureza; b) o ser humano está alienado de si mesmo; c) o ser humano está alienado de sua espécie" (Iasi, 2011, p. 22).

A consciência das massas, portanto, é a consciência das necessidades impostas violentamente pela forma social do capital. Nas palavras de Marx (apud Menegat, 2012, p. 66),

Não basta que as condições de trabalho apareçam num polo como capital e no outro polo, pessoas que nada têm para vender a não ser a sua força de 
trabalho. Não basta também forçarem-na a se vender voluntariamente. $\mathrm{Na}$ evolução da produção capitalista, desenvolve-se uma classe de trabalhadores que por educação, tradição, costume, reconhece as exigências daquele modo de produção como leis naturais evidentes.

E de que maneira a consciência, em sua forma elementar, se relaciona com a criminalização e o genocídio da juventude negra?

Ora, se o modo de produção capitalista em seu atual estágio de desenvolvimento produz um enorme exército de reserva ${ }^{14}$ incapaz de ser absorvido, em um momento de crise estrutural, em que as suas contradições são esgarçadas, o grande capital volta-se tão somente para sua lógica de autorreprodução, ampliando a mistificação das relações subsumidas ao capital.

A ofensiva neoconservadora aparece nesse estágio com uma função ideológica, que "reproduz um modo de ser fundado em valores historicamente preservados pela tradição e pelos costumes - no caso brasileiro - um modo de ser mantido pelas nossas elites, com seu racismo, seu preconceito de classe, seu horror ao comunismo" (Barroco, 2015, p. 624).

Desta feita, a função repressiva do Estado ${ }^{15}$ é expandida, contudo, em um Estado democrático de direito, a coerção não será utilizada sem que seja de alguma forma legitimada. Para tanto, ganham destaque na manipulação das consciências as esferas de reprodução da vida social, as quais apresentam como conteúdo essencial, "falando em termos inteiramente gerais e

14. Subescrevemos a análise de Antunes (2015, p. 787): “[...] me parece claro que para Marx o exército industrial de reserva é parte intrínseca da classe trabalhadora. A classe trabalhadora que está no desemprego, que é estrutural, no sentido da lógica destrutiva do capital, compreende o que Marx com muita qualidade delimitou os distintos elementos que compreendem o exército industrial de reserva, que hoje podemos chamar de "exército de reserva".

15. Mandel (1982, p. 333-334), ao analisar o Estado na fase do capitalismo tardio, classifica as suas principais funções da seguinte maneira: “1) criar as condições gerais de produção que não podem ser asseguradas pelas atividades privadas dos membros da classe dominante; 2) reprimir qualquer ameaça das classes dominadas ou de frações particulares das classes dominantes ao modo de produção corrente através do Exército, da polícia, do sistema judiciário e penitenciário; 3 ) integrar as classes dominadas, garantir que a ideologia da sociedade continue sendo a da classe dominante e, em consequência, que as classes exploradas aceitem sua própria exploração sem o exercício direto da repressão contra elas (porque acreditam que isso é inevitável ou que é 'dos males o menor', ou a 'vontade suprema', ou porque nem percebem a exploração)". 
abstratos", o convencimento de uma pessoa ou de um grupo de pessoas "a realizar, por sua parte, pores teleológicos concretos” (Lukács, 2013, p. 83)

Vejamos:

[...] o ser social é um complexo composto de complexos, cuja reprodução se encontra em variada e multifacetada interação com o processo de reprodução dos complexos parciais relativamente autônomos, sendo que à totalidade, no entanto, cabe uma influência predominante no âmbito dessas interações. (Lukács, 2013, p. 278)

Embora não possam ser adequadamente compreendidos se considerados isoladamente, dentre os complexos sociais parciais que constituem o espaço da reprodução, destacamos neste artigo a esfera jurídica e a linguagem, sobretudo a utilizada pela grande mídia controlada pelas classes dominantes.

Em relação à esfera jurídica, Lukács (2013) infere que ela responde a interesses de classe econômicos, ao mesmo tempo em que se diferencia e não se confunde com a economia. O direito é entendido, em sua particularidade, como uma esfera de ação teleológica que tem em vista não a relação direta com a natureza, mas o processo de convencimento da consciência, característica que, como vimos, constitui a categoria da reprodução.

Nesse sentido, há uma prioridade ontológica das relações socioeconômicas que não retira a sua função social. Logo, o direito exerce uma função na reprodução social na medida em que

a mediação jurídica faz parte do próprio cotidiano a partir do momento em que o Direito atua enquanto ideologia, o que ocorre, de maneira efetiva, somente na sociedade civil-burguesa. O Direito, pois, não atua somente quando a "normalidade" é ameaçada: a própria normalidade só se configura como tal pela mediação jurídica. (Sartori, 2010, p. 78)

Lukács (2013) considera que, ao mesmo tempo em que não se trata de um simples epifenômeno, o direito possui um caráter manipulatório cada vez mais presente na sociedade burguesa. Há contradições presentes no direito, uma vez que tratar dele é tratar do movimento do próprio real. 
A célula da sociedade capitalista — a mercadoria — é deixada intocada juntamente com a igualdade jurídica cujas raízes estão na realidade a que pretensamente se contrapõe: em verdade, a igualdade é um pressuposto da forma mercantil. Lukács admite que a ideia de justiça seja ambígua; assim, coloca de maneira dialética a preponderância das relações materiais: ao mesmo tempo em que aquilo que é questionado são as desigualdades da sociedade produtora de mercadorias, permanece-se na igualdade formal oriunda da forma mercantil. (Sartori, 2010, p. 113)

Acompanhando o movimento da própria sociedade, a reificação da esfera econômica é conduzida também para a esfera jurídica. Segundo Lukács (2013, p. 238) "o direito constitui uma forma específica do espelhamento, da reprodução consciente daquilo que sucede de facto na vida econômica". Por conseguinte, o autor húngaro afirma que o sistema jurídico não surge

do espelhamento da realidade, mas só pode ser sua manipulação homogeneizante de cunho conceitual-abstrato. Por outro lado, a coesão teórica do respectivo sistema jurídico positivo, essa sua falta de contraditoriedade oficialmente decretada, é mera aparência. (p. 239)

Outra contradição encontrada no direito refere-se à violência; na medida em que cabe a ele lidar com os conflitos sociais e retirá-la de campo, ao mesmo tempo que parece se opor a ela, nela se baseia. Desta forma, o sistema vigente do direito positivo opera fundado no seguinte método:

[...] manipular um turbilhão de contradições de tal maneira que disso surja não só um sistema unitário, mas um sistema capaz de regular na prática o acontecer social contraditório, tendendo para a sua otimização, capaz de mover-se elasticamente entre polos antinômicos — por exemplo, entre a pura força e a persuasão que chega às raias da moralidade - , visando implementar no curso das constantes variações do equilíbrio dentro de uma dominação de classe que se modifica de modo lento ou mais acelerado, as decisões em cada caso mais 
favoráveis para essa sociedade, que exerçam as influências mais favoráveis sobre a práxis social. (Lukács, 2013, p. 247) ${ }^{16}$

Destarte, ainda que inerentemente burguês, o direito se apresenta como algo neutro no que se refere aos conflitos de classes e, ao invocar as noções de sujeito de direito e igualdade, oculta as contradições da sociedade capitalista. ${ }^{17}$

Fica claro que, para isso, faz-se necessária uma técnica de manipulação bem própria, o que já basta para explicar o fato de que esse complexo só é capaz de se reproduzir se a sociedade renovar constantemente a produção dos "especialistas" (de juízes e advogados até policiais e carrascos) necessários para tal. Porém, a tarefa social vai ainda mais longe. Quanto mais evoluída for uma sociedade, quanto mais predominantes se tornarem dentro dela as categorias sociais, tanto maior a autonomia que a área do direito como um todo adquire na interação dos diversos complexos sociais. (Lukács, 2013, p. 247)

O direito, portanto, exerce papel fundamental no que podemos chamar de "barbárie civilizada", a qual se configura na medida em que "que a violência não é mais exercida de maneira espontânea, irracional e emocional pelos indivíduos, mas é monopolizada e centralizada pelo Estado" (Elias apud Lowy, 2000, p. 46).

O processo de criminalização, nos componentes de produção e de aplicação de normas penais, protege seletivamente os interesses das classes dominantes, pré-seleciona os indivíduos estigmatizáveis distribuídos pelas classes e categorias sociais subalternas e, portanto, administra a punição pela oposição de classe do autor, a variável independente que determina a imunidade das elites de poder econômico e político e a repressão das massas miserabilizadas e sem

16. "Por um lado, a força como garantia última dessa existência e unidade; por outro, a impossibilidade de basear unicamente no uso da força essa unicidade da práxis social controlada e garantida pelo direito" (Lukács, 2013, p. 246).

17. Sobre as categorias abstratas do direito, conforme a teoria geral do direito desenvolvida por Evgeni Pachukanis, cf. Teoria geral do direito e marxismo. 
poder das periferias urbanas, especialmente as camadas marginalizadas do mercado de trabalho, complementada pelas variáveis intervenientes da posição precária no mercado de trabalho e da subsocialização - fenômeno definido como administração diferencial da criminalidade. (Santos, 2008, p. 126)

Desse modo, o superencarceramento, decorrente do processo de criminalização seletiva, representa uma das faces da barbárie atual e é operado justamente pela esfera jurídica em conjunto com outras esferas do espaço da reprodução.

Embora não seja possível desenvolver uma reflexão mais profunda neste momento, é mister ressaltar que a comunicação social, sob todos os seus aspectos (interindividuais, institucionais e midiáticos), é outra esfera que possui um papel fundamental na manipulação da consciência em sua forma elementar.

No que tange ao processo de criminalização seletiva, a comunicação desempenha um relevante papel de imposição das representações sociais e a mídia atua como um instrumento que produz e reproduz estereótipos, ${ }^{18}$ manipulando as consciências. A perversidade contida nos discursos punitivos e criminalizantes, encontrados na grande mídia e nas redes sociais, revela o seu recorte classista e racial e divide a sociedade entre "cidadãos de bem" e bandidos.

Ao analisar a criminologia midiática, Zaffaroni (2013, p. 197) afirma que ela

cria a realidade de um mundo de pessoas decentes, diante de uma massa de criminoso, identificada através de estereótipos, que configuram um eles separado do resto da sociedade, por ser um conjunto de diferentes e maus. [...] Como para concluir que eles devem infundir muito medo e ser crível que seja ele o causador único de todas as nossas aflições. Por isso, para a TV, o único perigo que espreita nossas vidas e nossa tranquilidade são os adolescentes do bairro marginal, eles.

18. Cf. Suzane Jardim. 12 estereótipos racistas dos EUA que você já viu, mas não soube identificar. Disponível em: <https://voyager1.net/sociedade/estereotipos-racistas-dos-eua/>. Acesso em: 18 jan. 2018. 
Podemos citar como exemplo — dentre tantos outros ${ }^{19}$ de como essa questão se materializa no cotidiano da sociedade brasileira - a diferença de tratamento utilizada pelo Portal G1, principal site de notícias do país, em duas situações semelhantes. A primeira ocorreu uma semana antes e se refere à apreensão de um homem em um bairro periférico da cidade de Fortaleza, cujo título da notícia é "Polícia prende traficante com $10 \mathrm{~kg}$ de maconha em Fortaleza" (grifo nosso), enquanto a segunda anuncia "Polícia prende jovens de classe média com $300 \mathrm{~kg}$ de maconha no Rio" (grifo nosso). ${ }^{20}$

Nota-se, desta forma, como é construída a imagem do "criminoso" a partir da população pobre e periférica, sobretudo negra. Tal estereótipo é reforçado constantemente pelos meios de comunicação - cujos interesses visam à reprodução do capital — como potencial ameaça à manutenção da segurança pública, gerando na sociedade ondas de medo, que, como aponta Faustino (2012, p. 22),

são conscientemente incentivadas e sistematicamente exploradas como estratégia de controle a partir da legitimação da violência sistêmica. Ocorre que [...] as ondas de medo não são indistintamente distribuídas entre a classe trabalhadora como um todo, e muito menos aos pobres em geral.

Nesse sentido, "o racismo segue oferecendo aos aparatos de repressão os elementos ideológicos que legitimam o livre uso da força do Estado" (Faustino, 2012, p. 24). Na mesma perspectiva, o professor e jurista Silvio Almeida (informação verbal), ${ }^{21}$ ao analisar o racismo como elemento estrutural e estruturante das relações sociais que são determinadas pelo capitalismo, afirma que, nos momentos de crise e transformação econômica, na

19. Basta uma rápida pesquisa na rede social mais utilizada pela população brasileira e é possível identificar diversas páginas e grupos carregados de discursos de ódio. Muitos deles utilizam como nomenclatura o famigerado jargão "bandido bom é bandido morto" e cultuam abusos policiais e imagens chocantes de jovens, em sua maioria negros, mortos pela polícia.

20. Disponível em: $<$ http://www.pragmatismopolitico.com.br/2015/03/g1-ve-diferencas-entre-apanhados-com-drogas.html>. Acesso em: 12 mar. 2017.

21. Estado, direito e análise materialista do racismo. Disponível em: <https://www.youtube.com/ watch?v=Pyn40G76kBI>. Acesso em: 15 jan. 2018. 
história do mundo e do Brasil, ocorrem mudanças "nas estratégias de lidar com a questão racial", a qual assume formas específicas e manifestações distintas, a partir das particularidades da formação social de cada país e em cada contexto histórico.

Obviamente que, seja pelas vias da esfera jurídica ou da linguagem, a difusão desse processo de criminalização, que nos remete ao racismo científico da criminologia lombrosiana, utiliza-se de diversos meios de mistificação da realidade, assim como ocorre em outros processos da vida social sob o domínio do capital. No Brasil neoliberal, por exemplo,

ganhou evidência [...] o encarceramento de legitimação, essas prisões espetaculosas de alguns brancos ricos, que, como dizem Nilo Batista e Raúl Zaffaroni, "servem para encobrir ideologicamente a seletividade do sistema, que através de tais casos pode apresentar-se como igualitário". (Batista, 2010, p. 33)

Em síntese, trata-se do que Lukács (2013, p. 242) já explicava: “nenhum direito pode subsistir se não puder ser efetivado mediante a coerção, mas para que o seu funcionamento se dê com o mínimo de fricção é preciso que haja certa consonância entre seus vereditos na opinião pública”.

Por fim, podemos concluir que com a colaboração da mídia e a legitimação da esfera jurídica, "a acumulação capitalista e o neoliberalismo criaram as bases concretas para a reprodução social da barbárie manifesta em ideias, valores e comportamentos" (Barroco, 2015, p. 626), que instituem o terror em nome da "ordem". Como diz José Paulo Netto (2012), esgotadas as suas possibilidades civilizatórias, a ordem tardia do capital "só tem a oferecer, contemporaneamente, soluções barbarizantes para a vida social".

\section{Considerações finais}

As reflexões aqui trazidas, introdutoriamente, apontam que para compreender a relação entre as soluções bárbaras utilizadas pelo capital e a sua naturalização e reprodução no cotidiano da sociedade brasileira, é preciso 
analisá-la a partir da centralidade do trabalho, pois é a relação existente entre capital e trabalho que aliena, estanha e reifica as relações sociais.

Em tempos de crise estrutural, as contradições do modo de produção capitalista são esgarçadas, voltando-se tão somente à sua lógica de autorreprodução.

Por conseguinte, o controle social das massas que já não são mais funcionais ao capital ocorrem, na atualidade, em larga escala e de uma forma extremamente cruel: uma parte é presa e a outra é exterminada a céu aberto. No entanto, essas duas formas - superencarceramento e genocídio da juventude negra - , que visam evitar o desmoronamento social do capital, são vistas com naturalidade e reproduzidas no cotidiano da vida social brasileira.

Os discursos de ódio, o aumento dos linchamentos, os crimes contra a vida praticados pela polícia, sob o véu da suspeita e da legalidade, demonstram a materialidade do racismo enquanto ideologia a serviço do grande capital.

Nesse processo de manipulação da consciência em sua forma primeira de manifestação, tanto a esfera jurídica quanto os meios de comunicação controlados pela classe dominante possuem papel fundamental. Assim, sob a égide da legalidade, se houver qualquer ameaça ao acúmulo de riquezas e à manutenção das frações dominantes, o direito - inerentemente burguês - sempre irá operar em seu favor, exercendo papel fundamental na "barbárie civilizada". Destarte, as expressões contemporâneas mais evidentes da barbárie atual no Brasil configuram um Estado de exceção que, através do caráter manipulatório do direito, se diz democrático.

É evidente, portanto, a necessidade de compreender as particularidades pelas quais a luta de classes atravessa as várias esferas da vida social, através do sistema de mediações dominantes. Por fim, é preciso identificar os traços constitutivos do fenômeno social real em cada esfera da reprodução do ser social, de forma que assim possamos encontrar as estratégias para superar o atual modo de produção, que se materializa na dominação, na exploração, na violência e na barbárie; e a construção de uma nova forma social voltada para as reais necessidades humanas e sociais.

Recebido em 22/1/18 - Aprovado em 20/6/18 


\section{Referências bibliográficas}

ANTUNES, Ricardo. Adeus ao trabalho? 20 anos depois. Serviço Social \& Sociedade, São Paulo, n. 124, p. 773-799, out./dez. 2015.

. A dialética do trabalho: escritos de Marx e Engels. São Paulo: Expressão

Popular, 2013.

BARROCO, Maria Lucia Silva. Não passarão! Ofensiva neoconservadora e Serviço Social. Serviço Social \& Sociedade, São Paulo, n. 124, p. 623-636, out./dez. 2015.

BATISTA, Vera Malaguti; ABRAMOVAY, Pedro Vieira. Depois do grande encarceramento. Rio de Janeiro: Revan, 2010.

FAUSTINO, Deivison. O encarceramento em massa e os aspectos raciais da exploração de classe no Brasil. 2012. Disponível em: $<$ http://kilombagem.org/o-encarceramento-emmassa-e-os-aspectos-raciais-da-exploracao-de-classe-no-brasil-deivison-FAUSTINO />. Acesso em: 15 mar. 2017.

IASI, Mauro Luis. Reflexão sobre o processo de consciência. In: Ensaios sobre consciência e emancipação. São Paulo: Expressão Popular, 2011.

LUKÁCS, Gyorgy. Para uma ontologia do ser social II. São Paulo: Boitempo, 2013.

LOWY, Michel. Barbárie e Modernidade no século XX. In: LOWY, M. \& BENSAID, D. Marxismo, Modernidade, Utopia. São Paulo, Xamã, 2000, p. 46-56.

MANDEL, Ernest. O capitalismo tardio. São Paulo: Abril Cultural, 1982.

MARX, Karl; ENGELS, Friedrich. A ideologia alemã. São Paulo: Boitempo, 2007.

MENEGAT, Marildo. Estudos sobre ruínas. Rio de Janeiro: Revan, 2012.

NETTO, José Paulo. Crise do capital e consequências societárias. Serviço Social \& Sociedade, São Paulo, n. 111, p. 413-430, jul./set. 2012.

RUSCHE, Georg; KIRCHHEIMER, Otto. Punição e estrutura social. Rio de Janeiro: Revan, 2004.

SANTOS, Juarez Cirino dos. A criminologia radical. 3. ed. Curitiba: Lumen Juris, 2008. SARTORI, Vitor Bartoletti. Lukács e a crítica ontológica ao direito. São Paulo: Cortez, 2010. ZAFFARONI, Eugenio Bronislávovich Raul. A questão criminal. 1. ed. Rio de Janeiro: Revan, 2013.

\section{Nota da autora}

Jaqueline Garcez Buozi — Graduada pela Universidade Estadual Paulista (Unesp). E-mail: jaquelinegb2@gmail.com 